\title{
Current Overview of Assistance Bioethics Committees in Chile
}

\author{
Rodrigo Barra Novoa \\ Research group of the Laboratory of Innovation, Growth and Sustainability of the Andean Macro Region \\ Corresponding author email: rodrigo.barra.novoa@gmail.com \\ Karen Limari Castro \\ Research group of the Laboratory of Innovation, Growth and Sustainability of the Andean Macro Region \\ Pedro Limari Castro \\ Research group of the Laboratory of Innovation, Growth and Sustainability of the Andean Macro Region
}

\begin{abstract}
The article examines and analyzes the functioning of healthcare ethics committees in Chile. For this, through an extensive bibliographic review, parameters were established that allow indicating improvements to the system that regulates the Ethical-Assistance Committees (CEA) in the Latin American nation, based on a case study that corresponds to the University of Chile.

Keywords---Bioethics, CEA ethics, healthcare ethics, public health.
\end{abstract}

\section{Introduction}

Due to the rapid growth, the progress of technology and health science, new ethical and legal problems have been generated, as a result of which some questions arise: who makes decisions for the patient when he cannot? How are they made? These decisions? What are the best options when health and religion intersect? Who educates health personnel about the doctor-patient relationship? As well as many other questions. These problems posed by medicine, life sciences, and technologies are related to respect for the dignity (an essential issue in the new Chile) of the person, human rights, and fundamental freedoms, and is what leads to the conformation of Bioethics committees in Health Institutions (Vergara et al., 2015).

It is important to mention that the pioneer nations in creating clinical-care Bioethics committees were the United States, Spain, Brazil, and Argentina since they were countries that had high rates of lawsuits, most of them due to medical-surgical negligence. In the United States, after the Nuremberg trials, the Nuremberg Code addressed the issue of the protection of human subjects in experimental studies. Later, the Declaration of Helsinki (World Medical Association, 1964) insisted on the need to create bodies that would be in charge of ensuring the quality of research protocols. From this moment, the clinical trials committees (CEC) were born. In Europe, ethics-care committees (CEA) are much less numerous than in the United States. This is why it is important to make a comparison of the operation of bioethics committees in Chile and to make a comparative table with Spain since as the previous paragraph points out, this country was one of the first to form them (Carrese \& Sugarman, 2006; Petersen, 2013).

\section{Mission and Functions of the Healthcare Ethics Committee in Chile}

The committees are collegiate bodies of a consultative and interdisciplinary nature, created to analyze and advise on ethical conflicts that arise as a result of health care, to help improve the quality of care and protect the rights of people concerning it. The objective of the CEA is to methodically support and guide both professionals and patients and/or their families, concerning ethical problems that arise in the practice of medical care. Its scope of activity will include assistance, education, and Ethical Regulations, to establish recommendations in daily healthcare practice (Haines et al., 2006; Leigh-Hunt et al., 2017; Nakato et al., 2020). 
Of the Functions of the Ethics Committee:

The Ethics Committee must fulfill the following purposes:

1) Advise the authorities of this health establishment, in the safeguarding and observance of ethical values, addressing problems that in this matter arise from the practice of hospital medical care.

2) Analyze and regulate aspects concerning the doctor-patient relationship, respect for dignity, the right to life, and the spiritual rights of patients, as well as respect for their family relationship.

3) Formulate ethical recommendations on conflictive or risky situations, such as very high-risk surgeries or medical procedures, treatment of terminal patients, etc.

\section{Of the Functioning of the Ethics Committee}

The Ethics Committee will act in strict observance of the Political Constitution of the State, the international agreements and declarations signed by the State of Chile, the specific regulations established by the Code of Ethics of the Medical College of Chile, and the guidelines issued by the Ministry of Health, and for the fulfillment of its duties (Abel, 2006), it will be adjusted through the following organizational structure:

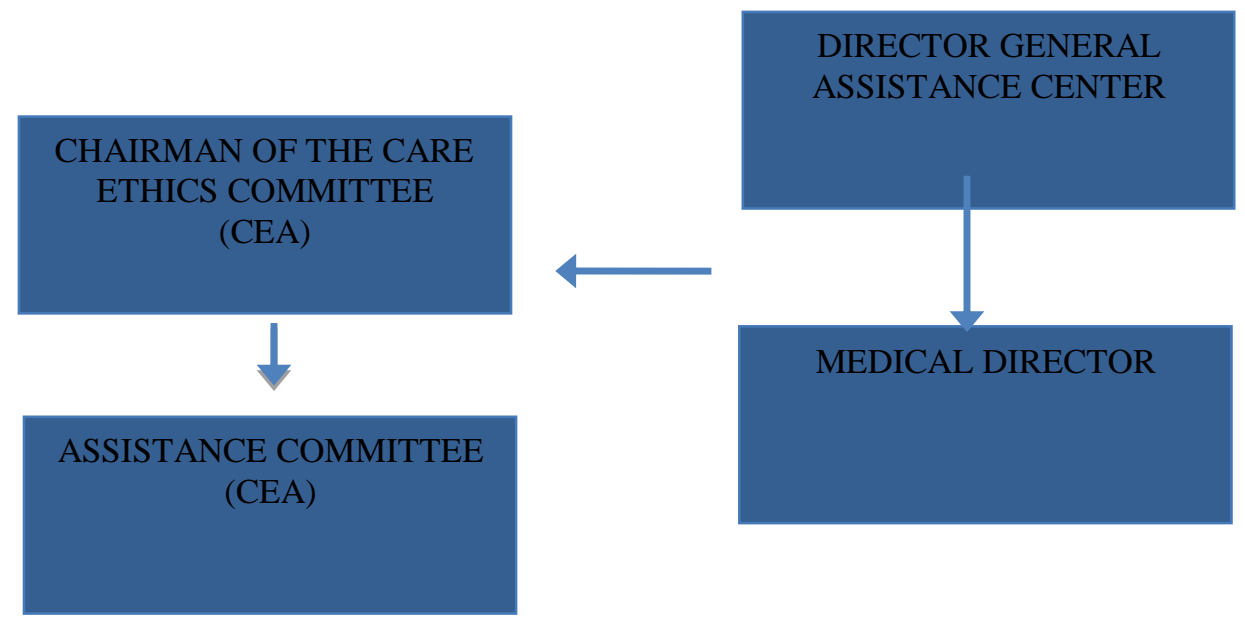

Figure 1. Organizational Structure of the Ethics Committee in a Hospital Center Source: Regulation of the Healthcare Ethics Committee, Clinical Las Condes

Main goal:

Examine and analyze the system as such in Chile, to determine if the operation is optimal within the framework of the functions that the ethics committees have by default.

\section{Secondary objectives:}

This is why we will proceed to go from the macro to the micro, contextualizing the CEA in Chile, to later present research results at the clinical hospital of the University of Chile.

a) Determine the context and structure of the ethics committees in Chile

b) Make assumptions that validate the operational mechanism of the ethics committees in Chile.

c) Analyze information based on a specific case study in Chile.

\section{Hypothesis:}

A) H1: That a group of 7 members are part of the healthcare ethics committee ensures its efficient performance.

B) H2: The credibility and authority of the healthcare ethics committees based on a 3-year tenure are positively linked to the effective fulfillment of their functions. 


\section{Methodology}

The proposed methodology for the development of the article is based on a rigorous bibliographic review that responds to the new needs of research in the field of operation of the healthcare ethics committees in Chile and examines the system that regulates the healthcare ethics committees (CEA).

a) Sources Used: A compilation of data will be carried out, both normative and of the structure of several healthcare ethics committees in Chile, both Public and Private.

b) For the above purposes, the following search engines were used: Google Scholar, and SciELO.

c) The criteria for selecting the documents in question have been based on the Quality of the content, that the origin corresponds to publications in scientific journals, as well as procedural rules established by internal regulations of the Government of Chile.

\section{Results and Discussion}

\section{Healthcare ethics committees in Chile}

In Chile, for example, there is no doubt that health care ethics committees are currently a necessity and a valuable contribution in improving the operating conditions of any hospital center (Couceiro \& Beca, 2006). A complex issue in the South American country is the complexity and difficulty of creating a multidisciplinary and "balanced" working group since, given the current situation, it is even more difficult to find members who are adequately representative of the respective communities. A case study of the results will be that of the Clinical Hospital of the University of Chile, which will be compared with the healthcare ethics committees of the Autonomous Community of Catalonia for general considerations and conclusions (Stahl \& Coeckelbergh, 2016; Ethics Committee of the American Society for Reproductive Medicine, 2015). Next, the structure of the Chilean healthcare ethics committee is denoted, to define a construct and subsequently carry out an evaluation, according to the methodology set out:

\section{Composition:}

The current structure of the CEA has changed little since the 2007 resolution appointing them, and it has a social worker, midwife, lawyer, and a community representative, in addition to four physicians (geriatrician, geneticist, surgeon, and gynecologist). In the past, there was a nurse, a pediatrician, a psychiatrist, an intensivist, and a geriatrician. To date, all current members have already completed their first three-year term, provided by the regulations of Law 20,584. It is believed that it is a strength that they remain serving in their capacity as members who renewed their term of appointment by the experience that is put at the service of the Committee, after having spent a long time in the task of constituting and serving it.

\section{Advisory function:}

During the 2013-2018 period, in addition to administrative and dissemination actions, instruments have been developed and improved that allow the Hospital to be offered a committee that today can respond in an ethicalclinical consultation modality of the 24-hour assistance type, to Through physical consultation sheets available in all nursing clinics and also in the virtual format in the TICARES support ${ }^{*}$ of the electronic medical record. Most of the inquiries received are sent in physical format and not, through the web. The consultation sheet is sent to the CEA by the aforementioned means and usually requires completion, due to the insufficient information it provides, which is necessary to know the case. Although these aspects have been improving over time (educational work), they still need to be done, as they continue to arrive incompletely. Since its inception, the work sessions have been held in ordinary meetings every 15 days and extraordinary sessions that call for the CEA to attend the patient's room in the shortest possible time, normally within the first 24 hours.

Reviewing what is available on the web of the inter-consultation formats of other health care committees, it can be said that there are common elements, such as those referring to the medical history and the matter that the committee wishes to consult. Other data, referring to the patient's competence, socioeconomic situation, the prognosis of the disease, family opinion, are data that the Committee of the "Hospital Clínico Universidad de Chile" has defined that it is its role to investigate or extract them from the interview with the patient and do not request it on

\footnotetext{
* Electronic System of Clinical Record, implemented in 2009.
} 
the sheet of our consultation. A decision that the Committee has made since its inception is, as far as possible, to always interview the patient or their family members. The first of the questions that are asked when receiving the consultation is if what is posed in it is within the competence of the Committee. Among the functions described for the CEA is to help in the decision-making of ethical-clinical situations of a certain patient. It is not uncommon; however, that he has been consulted for aspects that are clearly outside his task, such as complaints from patients or relatives, adverse events, drug theft, sexual harassment, etc.

Then an attempt is made to determine as precisely as possible what the exact question is being asked and why it is being asked. Who has the ethical problem? This consultative phase is normally resolved through a conversation with the professional or with the consulting family member if it is not clearly stated in the document presenting the case. The vast majority of the cases have been presented by the treating physicians, the scholarship holders, or some of the physicians who have cared for the patients during their hospitalization process. It is not often that other health professionals or patients seek the opinion of the committee.

As can be seen in Graph $\mathrm{N}^{\circ} 1$, the cases consulted have been growing in number and complexity in a sustained manner (among other reasons due to the strict application of the regulatory framework on the rights of patients, the new technologies available to the Hospital, etc.). To date, there has been a change in the consultation modality, in which approximately one-third of them must be resolved in extraordinary meetings, that is, immediately and in the patient's room.

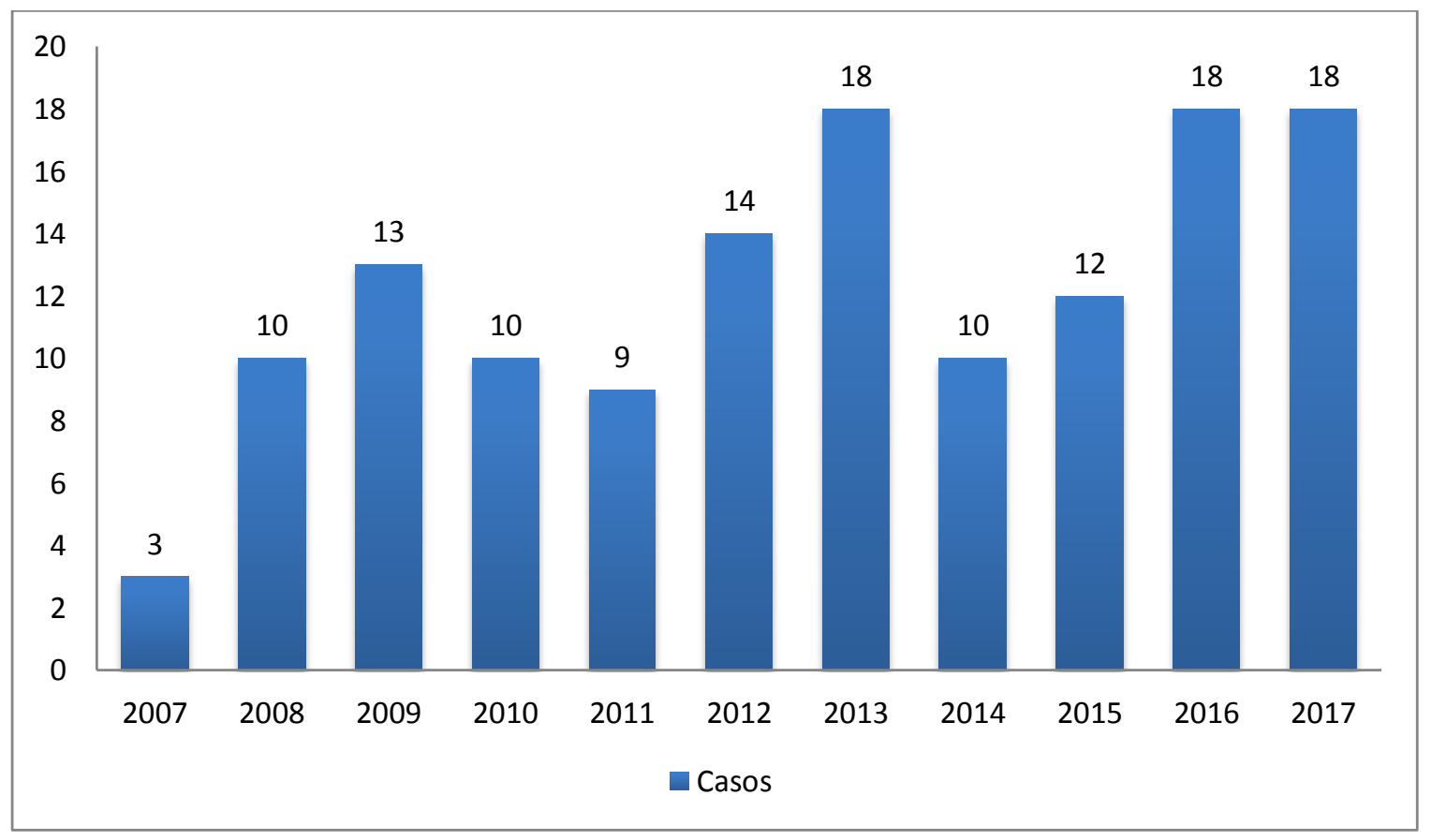

Graph 1. Variation of Cases 2007 - 2017

Source: Healthcare Ethics Committee Hospital Clínico Universidad de Chile

Once the case has been analyzed and a statement or recommendation has been issued, this report is addressed to the health teams that are directly related to the case raised. The answer is especially to whoever consults and who is responsible for making decisions, which may not coincide. Sometimes recommendations are made that often exceed the personal responsibility of the consultant and have implications for the work team, the department, or even the institution.

These responses can be inputs to establish procedures or regulations arising from the experience of solving previous cases in a later stage of maturity of the institution. In the regulations of the committees, it is considered that the directors of the establishment should also receive the documents of the Committee's recommendation and, in turn, receive the annual report together with the regional health authority. Two important aspects need to be defined from the first meetings: The first was related to opting for one of the various methodologies that facilitate the analysis and resolution of the ethical problems consulted. In the first place, assess the importance of knowing the 
facts in detail, then clarify the ethical problems faced concerning the conflicting values in each case, and, finally, define the duties that one has when suggesting a concrete action proposal.

The second step, once the methodology is selected, is to develop a systematic experience in the use of the deliberative method (which some have called "the method of bioethics"). The deliberative method specifies that once the investigation phase of the facts and values that coexist and overlap in each possible course of action in the eventual decisions to be made is completed, the patients (or their families) and the teams or teams must be interviewed treating physicians. Far from wanting to reduce the sessions to more or less diverse or documented opinions, we have proposed to carry out a "deliberative process", considering the opinions only after the first phase of documented and reflective analysis. We will always have a reasonable doubt about how thoroughly we have practiced this process (it has been said that deliberation is learned by deliberating); However, the first certainty is that the success of the deliberative process requires reflective and dialogue attitudes and capacities and that dialogue is not only a matter of reasons and arguments but of experiences.

Regarding attitudes, the result of this group will deliberate until possible is found in the fact that there have been few occasions in which the Decree that contemplates voting as a possibility in case of not reaching an agreement has been applied. The learning gained for each year of operation and each ethical-clinical situation consulted, makes it difficult to consider the recommendation that the committees renew their members every three years (duration of the period) without running the risk of losing a job that is enriched and prestigious with the experience itself. The most recurrent themes on which the consultations are based are related to different aspects of clinical work, being the following list:

a) Therapeutic proportionality analysis

b) Limitation and/or therapeutic adequacy (when to apply it, if the reflection is correct if it is justified if the limit of the therapeutic effort has been reached, etc.)

c) Problematic medical discharge and therapeutic continuity (discharge that cannot be materialized without failing to comply with planned care, forced discharge, administrative).

d) Transplantation and retransplantation (liver, heart, intestinal, kidney) in conditions of ethical doubt about justice, not maleficence.

e) Maternity cases (fetal therapy in utero, selective abortion, cancer, and pregnancy, patient refusal to interrupt her pregnancy with risk to her life).

f) Communication of the truth to patients (with different degrees of ability).

g) Valid rejection of study or treatment proposed by medical indication and rejected by patients with family disagreement.

h) Jehovah's Witnesses patients who refuse transfusions (procedures conditioned to eventual transfusions if there are complications).

i) Brain death, definition, and special situations (newborns, in patients connected to ECMO, in pregnant women).

j) Request by family members about treatments to a patient with a dubious medical indication (excessive risk, reckless, not indicated, experimental).

k) Transsexual patients requesting sex reassignment surgery (outside of comprehensive care programs, in other settings a request for à la carte surgery).

To the preceding list are added other queries that are related to protocols and criteria such as: compassionate use of medications, medical indications from non-institutional professionals, generation of documents that do not yet formally exist institutionally, for example, advance directives (will vital), valid rejection of treatments, etc. All these issues occur in the daily work of clinical services, however, in certain circumstances there are doubts about how it should proceed correctly so that the decision is made responding to ethical principles and the intention of who should implement it.

A general analysis of these cases could have in common certain recurring aspects that would explain their presentation to the Committee, beyond the medical-technical problem. It is common to find difficulties in doctorpatient communication, lack of treating physicians identified by the patient or family, adverse events at some point in the therapeutic process. All of these are objective faults in the practice of good medicine; However, they are also part of the fragility of the clinical relationship, of institutional decisions or policies, or of teams that have installed ways of working that make them possible or justify them. Many of these cases had to be discussed in more than one session. There are consultations with the Committee that in turn produce meetings with specialists and consultants for highly specialized topics, as well as meetings with the doctors and the treating team and meetings with the families. All of these meetings are added to the regular biweekly committee meeting series. 


\section{Normative function}

Either through requests to the plenary session or consultations directed as an expert consultancy, the Committee is required by the need to generate and/or adapt documents or internal regulations. Among the requests, it is worth mentioning the elaboration of the General Regulations of the Clinical Hospital, the norms for the implementation of Institutional Informed Consent Forms, the recommendations to define a treating physician, the teaching-care norms, revision of the agreement with a group of Witness patients Jehovah and compassionate use of medicines. Additionally, studies of programs have been commissioned on which the Hospital Directorate had to pronounce on the freezing of embryos for in vitro fertilization, on facial transplantation of components, among others.

\section{Teaching function}

About the other functions assigned to the healthcare ethics committees, in addition to their advisory and normative function, there is the teaching function. In this mission, it has been able to benefit as a Committee and as a Hospital close to the Faculty of Medicine and its Department of Bioethics and Medical Humanities. The teachers that compose it and their capacities, contacts, and disposition to reflect, have been fundamental to offer a service both within the Hospital and outside it. The teaching activity of the Faculty of Medicine has relegated the training activity of the Committee itself to formal induction actions for scholarship holders and meetings with small groups of academics or officials; however, the committee, in turn, has been incorporated as a permanent member in institutional activities of clinical safety and the Complaints Committee. In this case study, the HCUCH, being an accredited institution, is required to demonstrate its concern for the dignity of the patient, as the first quality verifier, and in the same way, knowledge of medical equipment and the existence and operation of a Hospital or Care Ethics Committee.

\section{Final Considerations}

Based on the exposed realities, in a general framework, it has been possible that the CEA - Healthcare Ethics Committee in Chile be clear about your mission and its limits. This has made it possible to focus on those issues and queries that are relevant and not be distracted by analyzes that do not correspond to them, such as making judgments about professional conduct. Additionally, the working groups have had the maturity not to fall into circular discussions. The same has happened with the degree of independence in decision-making or in arguments, which are not based on doctrinal, political, or managerial opinions.

To the time to take stock of the work of the CEA, things remain pending. One of them is to achieve a better position of this as a reference for consultation and therefore be more requested than it has been in Chile until now. Consolidation will be achieved gradually as decisions incorporate the family, and the communication channels between the "clinic and family network" area are as clear, close, and empathetic as possible.

\section{Conclusions}

Finally, given the hypotheses presented, the following can be concluded:

Based on Hypothesis No. 1: The regulations in Chile, regarding the number of members of the CEA, are regulated, it is important since what must always prevail is the value of "objectivity". However, quantity does not in itself ensure quality, and that is why all these members must be convinced that their work, regardless of their personal choices, is carried out in a democratic and plural society and that they cannot impose their personal preferences or ethical choices on patients or healthcare users. In other words, they must have a clear concept of what Civil Ethics represents, in which context they must assume the criteria required of all and respect those others that belong to a legitimate hierarchy of values, recognized by current legislation. Furthermore, this activity in Chile is done voluntarily, that is, it does not have a monetary concept, which is why it has been crucial to monitor the work of the 7 members of the healthcare ethics committee. Given the above, there is no positive relationship between the number of CEA members and its efficiency.

Concerning Hypothesis No. 2, given the information collected, it can be deduced that in Chile, rotation is associated with transparency so that each period assumes members with different positions, with other knowledge, and steeped in current medicine. However, given that the work carried out by the CEA is so rigorous and delicate, it is estimated that permanence should at least consider a cycle of 3 continuous periods since the idea is to be able to 
consolidate the potential of the CEA that is being formed, and the way to strengthen it in your decision making is to be as technical as possible and based on experience. For this reason, there must not be a clear positive relationship between a 3-year stay ensuring "credibility" and the effectiveness of the health care committee.

\section{References}

Abel, F. (2006). Care ethics committees. In Anales del sistema sanitario de Navarra (Vol. 29, pp. 75-83).

Carrese, J. A., \& Sugarman, J. (2006). The inescapable relevance of bioethics for the practicing clinician. Chest, 130(6), 1864-1872. https://doi.org/10.1378/chest.130.6.1864

Couceiro, A., \& Beca, JP (2006). The Healthcare Ethics Committees and the legal repercussions of their reports. Medical Journal of Chile, 134 (4), 517-519.

Ethics Committee of the American Society for Reproductive Medicine. (2015). Access to fertility services by transgender persons: an Ethics Committee opinion. Fertility and Sterility, 104(5), 1111-1115. https://doi.org/10.1016/j.fertnstert.2015.08.021

Haines, A., Kovats, R. S., Campbell-Lendrum, D., \& Corvalán, C. (2006). Climate change and human health: impacts, vulnerability and public health. Public health, 120(7), 585-596. https://doi.org/10.1016/j.puhe.2006.01.002

Leigh-Hunt, N., Bagguley, D., Bash, K., Turner, V., Turnbull, S., Valtorta, N., \& Caan, W. (2017). An overview of systematic reviews on the public health consequences of social isolation and loneliness. Public health, 152, 157171. https://doi.org/10.1016/j.puhe.2017.07.035

Nakato, J., Mazibuko, N. E., \& James, S. (2020). Antecedents influencing effective talent management in public health institutions in Uganda. Journal of Contemporary Management, 17(2), 601-631.

Petersen, A. (2013). From bioethics to a sociology of bio-knowledge. Social Science \& Medicine, 98, 264-270. https://doi.org/10.1016/j.socscimed.2012.12.030

Stahl, B. C., \& Coeckelbergh, M. (2016). Ethics of healthcare robotics: Towards responsible research and innovation. Robotics and Autonomous Systems, 86, 152-161. https://doi.org/10.1016/j.robot.2016.08.018

Vergara, PR, Massa, AA, \& Santos, MJ (2015). The Bioethics National Commission in Chile: a pending task. Contributions from the experience of National Bioethics commissions of Mexico and Italy / The National Bioethics Commission of Chile: a pending task. Contributions from the experience of the National Bioethics Commissions of Mexico and Italy / A Comissao Nacional de Bioetica do Chile: uma tarefa pendente. Contributors of experience from the national comissoes de bioetica do Mexico e da Italia. Acta Bioethica, 21 (1), 73-82. 